\title{
Isozymes in Ananas (Pineapple): Genetics and Usefulness in Taxonomy
}

\author{
M.G. DeWald, G.A. Moore ${ }^{1}$, and W.B. Sherman \\ Fruit Crops Department, Institute of Food and Agricultural Sciences, University of Florida, \\ Gainesville, FL 32611
}

Additional index words. isozyme polymorphism, Ananas comosus, peroxidase, phosphoglucomutase

\begin{abstract}
Genetically characterized isozyme loci are useful for taxonomic studies. In an initial study a few Ananas genotypes were used to determine which enzyme systems would give well-resolved banding patterns on starch gels. The enzyme-staining systems that resulted in well-resolved banding patterns were used to survey more Ananas genotypes to identify and characterize isozyme polymorphism. Genetic studies were performed using seedling populations to determine the basis of variability observed among genotypes. Two peroxidase loci and three phosphoglucomutase loci were identified and characterized. Information from these studies, was used to formulate a system by which species and plant introductions could be identified and distinguished.
\end{abstract}

The taxonomy of the Ananas genus has been the subject of much debate and speculation (Antoni, 1983; Collins, 1960; Smith and Downs, 1979). Species are generally classified according to floral, fruit, and leaf morphology. However, this method of classification has proven to be unsatisfactory for some feral types because they do not fit clearly into any particular species on the basis of these characteristics.

Characterization of plants based on electrophoretic variation of isozymes has been a powerful technique to separate and classify genotypes in many species (Tanksley and Orton, 1983). We found no reports of the genetic characterization of isozyme loci in Ananas; however, we have previously reported that isozyme banding patterns can be used to distinguish pineapple [A. conrosus (L.) Merr.] cultivars (DeWald et al., 1988). The main objective of the current study was to classify Ananas spp. and plant introductions on the basis of isozyme polymorphisms. The approach was to first identify well-resolved enzyme systems in Ananas and then to determine the genetic basis of the observed banding patterns.

\section{Materials and Methods}

Genotypes used. With the exception of A. fritzmueller (Camargo), which was not available in any of the major world collections, all of the Ananas spp. were included in this study (Table 1). Typically, two specimen plants of each species were used for analysis. The exception was A. comosus, the edible pineapple, where 29 cultivars were surveyed. These cultivars are the most economically important ones in use worldwide. The Ananas genotypes listed in Table 2 were either introduced by M.G.D. or obtained from the collection at the U.S. Dept. of Agriculture (USDA) Subtropical Horticultural Research Unit, Miami. Most of these accessions were collected in southern Venezuela and northern Brazil, an area that has been suggested as the major center of diversification for the Ananas genus (Leal and Antoni, 1980). Pineapple accessions were assigned to a given Ananas spp. based on floral and foliar characters (Smith and Downs, 1979). High levels of phenotypic variation were present for several characters.

Received for publication 28 Dec. 1990. Accepted for publication 27 Dec. 1991. Florida Agr. Ext. Sta. J. Ser. no. R-01697. The cost of publishing this paper was defrayed in part by the payment of page charges. Under postal regulations, this paper therefore must be hereby marked advertisement solely to indicate this fact.

'To whom reprint requests should be addressed.
Table 1. PER and PGM isozyme banding patterns observed for $A n$ anas species.

\begin{tabular}{|c|c|c|c|c|c|}
\hline \multirow[b]{2}{*}{ Species } & \multicolumn{5}{|c|}{ Isozyme genotypes ${ }^{z}$} \\
\hline & Per-2 & Per-3 & $P g m-1$ & $P g m-2$ & $P g m-3$ \\
\hline \multicolumn{6}{|l|}{ A. ananassoides (Baker) } \\
\hline L.B. Smith & FF & FS & MS & SS & FS? ${ }^{y}$ \\
\hline \multicolumn{6}{|l|}{ A. bracteatus var tricolor } \\
\hline (Bertoni) L.B. Smith & FS? & FF & MS & SS & SS \\
\hline \multirow[t]{3}{*}{ A. comosus (L.) Merr. } & FF & $\mathrm{FF}$ & FM & $\mathrm{FF}$ & $\mathrm{FF}$ \\
\hline & FS & FS & FS & FS & FS \\
\hline & SS & SS & MS & SS & SS \\
\hline A. lucidus Miller & FF & SS & SS & SS & SS \\
\hline \multicolumn{6}{|l|}{ A. monstrosus ${ }^{\mathbf{x}}$ (Carrière) } \\
\hline \multirow[t]{2}{*}{ L.B. Smith } & $\mathrm{FF}$ & FS & FM & FF & SS \\
\hline & FF & FF & SS & SS & SS \\
\hline \multicolumn{6}{|l|}{ A. nanus (L.B. Smith) } \\
\hline L.B. Smith & SS & FF? & SS & SS? & SS? \\
\hline \multicolumn{6}{|l|}{ A. parguazensis Camargo \& } \\
\hline L.B. Smith & $--\cdot$ & $\cdots$ & SS & FS? & SS \\
\hline
\end{tabular}

${ }^{\mathrm{z}} \mathrm{F}=$ the fastest migrating allele at the locus; $\mathrm{M}=$ an intermediately migrating allele; $\mathrm{S}=$ the most slowly migrating allele.

${ }^{y}$ ? indicates a doubtful determination; --- indicates data not available.

'Plants from two cultivars that resemble this species were analyzed.

Genetic studies were based on isozymic analysis of the Ananas germplasm liseted in Table 1 . In addition, two seedling populations were obtained from a commercial planting of $A$. comosus 'Smooth Cayenne' and 'Cambray' growing in adjacent fields in northwestern Ecuador. These seedling populations were assumed to represent reciprocal crosses between 'Smooth Cayenne' and 'Cambray'. This assumption was based on the reported self-incompatibility of pineapple (Brewbaker and Gorrez, 1967). Seeds were taken from mature fruit, rinsed in water, airdried, and scarified in sulfuric acid for 30 to $60 \mathrm{sec}$ followed by a rinse in sterile water. Seeds were germinated in covered petri dishes containing a sterile soil mixture. Seedlings were transplanted to pots and moved to a greenhouse after gradual acclimation. All plants were kept at Gainesville, Fla., under greenhouse conditions during the winter and outdoors the rest of the year.

Starch gel electrophoresis and isozyme staining. A 10\% (w/v)

Abbreviations: F, fast band; FF, fast-migrating band; FS, fast- and slow-migrating bands; PER, peroxidase; PGM, phosphoglucomutase; PI, plant introduction; S, slow band; SOD, superoxide dismutase; SS, slow-migrating band. 
Table 2. PGM isozyme banding patterns observed in Ananas plant introductions (PIs).

\begin{tabular}{|c|c|c|c|c|}
\hline \multirow[b]{2}{*}{ Species and type } & \multirow[b]{2}{*}{$\mathrm{PI}^{\mathrm{y}}$} & \multicolumn{3}{|c|}{ Isozyme genotypes $^{2}$} \\
\hline & & $P g m-1$ & $P g m-2$ & $P g m-3$ \\
\hline \multicolumn{5}{|l|}{ A. comosus } \\
\hline \multirow[t]{2}{*}{ Abacaki } & 095 & FF & FS $?^{x}$ & SS \\
\hline & 192 & MS & $\mathrm{FF}$ & FF \\
\hline \multirow[t]{3}{*}{ Maipure } & 092-1 & FS & FF & SS \\
\hline & 093 & FM & FS? & SS \\
\hline & 126 & MS & FF & FF \\
\hline \multirow[t]{4}{*}{. } & 196 & MS & FS & FS \\
\hline & 487439 & MS & FS & FS \\
\hline & 487440 & MS & FS & FS \\
\hline & 487433 & $\mathrm{MM}$ & FS & SS \\
\hline & 487445 & MS & FS & FS \\
\hline \multirow{6}{*}{ Spanish } & $072-1$ & ML & FS & SS \\
\hline & 085 & SL & FF & FF \\
\hline & 086 & MS & FF & FS \\
\hline & $092-2$ & SS & FS & SS \\
\hline & 110 & FS & FS? & FS? \\
\hline & 487442 & MS & SS & SS \\
\hline \multirow[t]{3}{*}{ A. ananassoides } & 046 & MS & SS? & FS \\
\hline & 079 & MS & SS & SS \\
\hline & 094 & MS & SS & $\mathrm{FF}$ \\
\hline \multirow[t]{2}{*}{ A. parguazensis } & 097 & SS & FS & FS \\
\hline & 108 & SS & FF & SS \\
\hline A. nanus & 064 & SS & SS? & SS \\
\hline \multirow[t]{7}{*}{ Others $^{w}$} & 115 & PS & SS? & FF? \\
\hline & 116 & SS & FS? & SS \\
\hline & 117 & SS & FS & FS \\
\hline & 188 & MS & FS & SS \\
\hline & 189 & SS & FS & $\mathrm{FF}$ \\
\hline & 193 & FS & $\mathrm{FF}$ & FF? \\
\hline & 27285 & MS & SS & SS \\
\hline
\end{tabular}

${ }^{2}$ For Pgm-2 and Pgm-3, F = the fastest migrating allele at the locus; $\mathrm{M}=$ an intermediately migrating allele; $\mathrm{S}=$ the most slowly migrating allele. At Pgm-1, two additional alleles are present; L, which migrates more slowly than $\mathrm{S}$, and $\mathrm{P}$, which migrates more rapidly than F

'PIs with five or six digit numbers were from the Miami collection, while PIs with three digit numbers were collected in Venezuela.

${ }^{x}$ ? indicates a doubtful determination.

'Botanical characteristics of the plant do not fit any of the valid species.

starch gel consisting of a 2:1 mixture of Sigma and Connaught (Fisher Scientific, Orlando, Fla.) hydrolyzed potato starch was used for all assays. Gel volume was $300 \mathrm{ml}$ in a $19 \times 19 \times$ 0.5 -cm gel mold. Six electrophoretic buffer systems were tested: 1) histidine/citrate, pH 5.7 (H buffer) (Cardy et al., 1981); 2) the same system, $\mathrm{pH} 6.3 ; 3$ ) tris/citrate, $\mathrm{pH} 7.0$ (electrode buffer: $50 \mathrm{~mm}$ trizma base, $16 \mathrm{~mm}$ citric acid; gel buffer: one part electrode buffer to two parts $\mathrm{H}_{2} \mathrm{O}$ ); 4) lithium borate/tris citrate (Scandalous, 1969); 5) tris/borate (electrode buffer: $38 \mathrm{~mm}$ trizma base, 2 mm citric acid, pH 8.6; gel solution $30 \mathrm{~mm}$ boric acid, $\mathrm{pH} 8.5$ ); and 6) tris/borate/EDTA, $\mathrm{pH} 8.6$, designated $\mathrm{K}$ by Loukas and Pontikis (1979). Most enzyme-staining solutions were as given. by Vallejos (1983). Exceptions were endopeptidase (EC 3.4.22.1) (Melville and Scandalios, 1972), formate dehydrogenase (EC 1.2.1.2) (Wendel and Parks, 1982), creatine kinase (EC 2.7.3.2) and hexokinase (EC 2.7.1.1) (Shaw and Prasad, 1970), malate dehydrogenase (EC 1.1.1.37) (Cardy et al., 1981), and peroxidase (EC 1.11.1.7) (Durham et al., 1987). Staining solutions modified in our laboratory from Vallejos (1983) included acid phosphatase (EC 3.1.3.2; $100 \mathrm{mg} \beta$-napthyl acid phosphate, $50 \mathrm{mg}$ Fast Black K salt, $100 \mathrm{ml} 0.1 \mathrm{~m}$ sodium acetate, $\mathrm{pH}$ 4.7), alkaline phosphatase (EC 3.1.3.1; $100 \mathrm{mg} \alpha-$ napthyl acid phosphate, $100 \mathrm{mg}$ Fast Blue RR salt, $100 \mathrm{ml} 0.1$ $\mathrm{M}$ Tris $\cdot \mathrm{HCl}, \mathrm{pH} 8.5$ ), aspartate aminotransferase (EC 2.6.1. 1; $500 \mathrm{mg}$ aspartic acid, $70 \mathrm{mg} \alpha$-ketoglutarate, $50 \mathrm{mg}$ pyridoxal5'-phosphate, $200 \mathrm{mg}$ Fast Blue BB salt, $100 \mathrm{ml} 0.1 \mathrm{~m}$ Tris.HCl, $\mathrm{pH}$ 8.0), phosphoglucomutase [PGM; EC 2.7.5.1; $500 \mathrm{mg}$ glucose-1-phosphate, $20 \mathrm{mg}$ NADP, $30 \mathrm{mg} 3$-[4,5-dimethylthiazol2-yl]-2,5-diphenyltetrazolium bromide (MTT), $4 \mathrm{mg}$ phenazine methosulfate (PMS), $100 \mathrm{mg} \mathrm{MgCl}, 100 \mathrm{ml} 0.1 \mathrm{~m}$ Tris. $\mathrm{HCl}$, $\mathrm{pH}$ 8.0, 40 units glucose-6-phosphate dehydrogenase; EC 2.1.2.49], and phosphohexose isomerase (EC 5.3.1.9; $100 \mathrm{mg}$ fructose-6-phosphate, $10 \mathrm{mg}$ NADP, $20 \mathrm{mg}$ MTT, $4 \mathrm{mg}$ PMS,

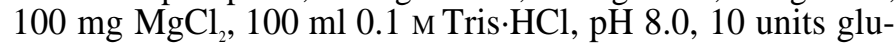
cose-6-phosphate dehydrogenase).

Leaf sap was used directly for isozyme analysis. No improvement in either resolution or stain intensity was observed with extraction buffers containing tris citrate at $0.1 ; 0.2$, and $1.0 \mathrm{M}$, $\mathrm{pH} 7.0$ or 8.0 ; or 4 mM Na${ }_{2}$ EDTA. All leaf samples were taken from the fourth new leaf and were used immediately or stored in plastic bags at $4 \mathrm{C}$ for later use. Samples were used within 7 days of collection, although no decrease in activity was detected for any enzyme tested for up to 3 weeks in storage. Leaf sap was expressed from the proximal portion of the adaxial surface of the lamina, using a pestle and a filter paper wick (Whatman No. $3,4 \times 8 \mathrm{~mm}$ ). The white waxy epidermis and underlying layer of fibers were scraped from the leaf surface to aid in leafsap absorption into the wick.

Electrophoresis was carried out under constant voltage at 4C. Optimal power settings and running times varied with the enzyme assayed as discussed below. The relative migrations of bands were calculated using the 7-cm front $\left(R_{f}\right)$ or the $14-\mathrm{cm}$ gel length $\left(\mathrm{R}_{\mathrm{m}}\right)$. Segregation at identified loci and the possibility of genetic linkage between loci were evaluated by $x^{2}$ analysis.

\section{Results and Discussion}

Selection of electrophoretic buffers and enzyme systems. This initial study involved the testing of 37 enzyme-staining systems and six buffer systems using a few of the Ananas types. No activity was detected on any buffer system for the following 18 enzymes: adenylate kinase (EC 2.7.4.3), alcohol dehydrogenase (EC 1.1.1.1), aldolase (EC 4.1.2.13), alkaline phosphatase (EC 3.1.3.1), $\alpha$-amylase (EC 3.2.1.1), ascorbate oxidase (EC 1.10.3.3), catalase (EC 1.11.1.6), creatine kinase, diaphorase (EC 1.6.4.3), endopeptidase, fumarase (EC 4.2.1.2), galactose dehydrogenase (EC 1.1.1.48), $\beta$-glucosidase (EC 3.2.1.21), hexokinase, laccase (EC 1.10.3.2), lactate dehydrogenase (EC 1.1.1.27), pyruvate kinase (EC 2.7.1.40), and xanthine dehydrogenase (EC 1.2.1.37). The following 11 additional enzyme systems showed limited resolution or enzyme-staining activity: formate dehydrogenase, $\beta$-galactosidase (EC 3.2. 1.23), and urease (EC 3.5.1.5) showed activity but no discrete banding; esterase (EC 3.1.1.2) and glutathione reductase (EC 1.6.4.2) yielded poorly resolved banding patterns that did not appear to vary between the genotypes tested; acid phosphatase, aspartate aminotransferase, glucose-6-phosphate dehydrogenase, leucine aminopeptidase (EC 3.4.11.1), malic enzyme, and shikimate dehydrogenase (EC 1.1. 1.25) gave poorly resolved banding patterns with some variable activity among genotypes.

High resolution was obtained for eight enzyme systems: isocitrate dehydrogenase (IDH; EC 1.1.1.42), malate dehydrogenase (MDH), peroxidase (PER), PGM, 6-phosphogluconate dehydrogenase (PGD; EC 1.1.1.44), glucose phosphate isomerase (GPI; EC 5.3.1.9), superoxide dismutase (SOD; EC 
1.15.1.1), and triose phosphate isomerase (TPI; EC 5.3.1.1). IDH, MDH, PGM, PGD, and GPI were best resolved when H buffer was used. For IDH and PGM, the $\mathrm{pH}$ of the $\mathrm{H}$ buffer was modified to 6.3. Gels were run at a constant voltage of 300 $\mathrm{V}$, with initial $\mathrm{mA}$ readings of 40 to 45 , and voltage was changed manually during electrophoresis to maintain total power readings of 12.0 to 13.5. PER, SOD, and TPI resolved best in K buffer. Initial V and $\mathrm{mA}$ readings were 250 and 25 to 34 , respectively, with total power maintained at 6.25 to 8.5 .

These eight enzymes were used to survey the genotypes listed in Table 1. Monomorphic banding patterns were obtained in five of the staining systems: IDH, PGD, PHI, SOD, and TPI. When gels were stained for MDH, one large anodal region consisting of many closely adjacent bands was observed. Six of the bands were well resolved, but the two fastest migrating bands were the only ones to show clear variation. The genetic basis of this variability "could not be deduced from the plant populations available for this study.

Variable; well-resolved banding patterns were observed for two enzyme systems: PER (Table 1) and PGM (Tables 1 and 2). Hypotheses to explain the observed variability in these enzyme systems were based on the banding patterns observed in the two segregating populations of plants from putative reciprocal crosses between 'Smooth Cayenne' and 'Cambray'.

Peroxidase. Three regions of activity were observed in all genotypes tested: two cathodal and one anodal (Fig. 1). The region of activity designated Per- 1 extended from $R_{f} 0.28$ to $R_{t}$ 0.26 and appeared to be variable between genotypes, but the resolution of bands in this region was often not clear. The other two variable regions. consisted of a single fast-migrating band

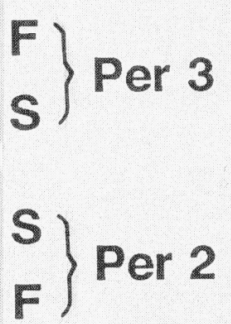

Fig. 1. PER banding patterns observed in pineapple. Anode is at bottom of figure.
(FF), a single slow-migrating band (SS), or a combination of the two (FS). The fast band of Per-2 was at $\mathrm{R}_{\mathrm{f}} 0.11$, and the slow band was at $R_{r} 0.04$. The fast band for the anodally migrating Per-3 was at $\mathrm{R}_{\mathrm{f}} 0.07$ and the slow band at $\mathrm{R}_{\mathrm{f}} 0.04$. Zones of activity with no defined bands were observed between $\mathrm{R}_{\mathrm{r}} 0.11$ to 0.25 and 0.32 to 0.38 .

The variability detected for PER may be explained by a model of a monomeric enzyme system with two alleles ( $\mathrm{F}$ and $\mathrm{S})$ at each of two loci (Per-2 and Per-3). Progeny produced from the cross with 'Smooth Cayenne' as the distillate parent showed a 1:1 segregation of FS and FF phenotypes for both Per-2 and Per-3, which would be expected if parents of the seedlings were homozygous (FF) and heterozygous (FS), respectively, for the alleles at the loci (Table 3; Fig. 2A). This was the case with 'Smooth Cayenne' (FF) and 'Cambray' (FS).

Seedlings obtained from open-pollinated crosses with 'Cambray' as the seed parent and 'Smooth Cayenne' as the putative pollen parent were expected to show a similar type of segregation, since this would be the reciprocal cross of the one described above and these were the only two cultivars growing in the region. Instead, progeny from the 'Cambray' female parent segregated in a 1:2:1 (FF : FS : SS) ratio for both Per-2 and Per-3, which indicates a cross between plants heterozygous at these two loci (Table 3; Fig. 2B). The banding patterns obtained from this progeny suggested that 'Smooth Cayenne' did not participate in the cross and that the 'Cambray' seedlings are most likely the result of selfing.

Phosphoglucomutase. Three anodal regions (Pgm-1, Pgm-2, and $P g m-3$ ) of well-resolved variable bands were observed in all of the genotypes tested (Fig. 3). Five bands, designated F, $\mathrm{S}, \mathrm{L}, \mathrm{M}$, and $\mathrm{P}$, were observed in the Pgm-1 region in the genotypes surveyed (Fig. 4). Only one or two of these bands were ever observed in a single individual. Pgm-2 and Pgm-3 both exhibited the same variable banding pattern consisting of a single fast-migrating band (FF), a single slow-migrating band (SS), or a combination of the two (FS) (Fig. 3). The five bands for Pgm-1 were at $\mathrm{R}_{\mathrm{m}} 0.15(\mathrm{~L}), 0.21(\mathrm{~S}), 0.25(\mathrm{M}), 0.29(\mathrm{~F})$, and $0.34(\mathrm{P})$. The fast band (F) for Pgm-2 was at $\mathrm{R}_{\mathrm{m}} 0.34$ and the slow band (S) was at $\mathrm{R}_{\mathrm{m}} 0.29$. The $\mathrm{F}$ for $P g m-3$ was at $\mathrm{R}_{\mathrm{m}}$ 0.41 and the $S$ was at $R_{m} 0.34$.

Most plant species possess either one or two PGM loci. An

Table 3. Genotypic ratios and $x^{2}$ goodness-of-fit values for five isozyme loci in pineapple.

\begin{tabular}{|c|c|c|c|c|c|c|c|}
\hline \multirow[b]{2}{*}{ Loci investigated } & \multicolumn{4}{|c|}{ Segregation classes $^{\mathbf{z}}$} & \multirow[b]{2}{*}{ Test ratio } & \multirow[b]{2}{*}{$\chi^{2}$} & \multirow[b]{2}{*}{$P$ value } \\
\hline & FF & FS & MS & SS & & & \\
\hline \multicolumn{8}{|c|}{ Smooth Cayenne seedlings ${ }^{y}$} \\
\hline Per-2 (FF $\times$ FS) & 12 & 16 &.-- & --- & $1: 1$ & 0.571 & $0.50-0.25$ \\
\hline Per-3 (FF × FS) & 17 & 11 & -- & -- & $1: 1$ & 1.285 & $0.50-0.25$ \\
\hline$P g m-1$ (FM $\times$ SS) & $\ldots$ & 13 & 15 & -- & $1: 1$ & 0.142 & $0.75-0.50$ \\
\hline$P g m-2(\mathrm{FF} \times \mathrm{FS})$ & 10 & 18 & -- & -- & $1: 1$ & 2.285 & $0.25-0.10$ \\
\hline$P g m-3$ (SS $\times$ FS) & $=-$ & 10 & $-\cdots$ & 18 & $1: 1$ & 2.285 & $0.25-0.10$ \\
\hline \multicolumn{8}{|l|}{ Cambray seedlings ${ }^{y}$} \\
\hline$P e r-2($ FS $\times$ FS $)$ & 5 & 10 & --- & 5 & $1: 2: 1$ & 0.000 & 1.000 \\
\hline Per-3 (FS x FS) & 4 & 11 & $\ldots$ & 5 & $1: 2: 1$ & 0.100 & $0.90-0.75$ \\
\hline$P g m-1$ (SS $\times$ SS $)$ & -- & $\cdots$ & -- & 20 & $\ldots$ & & \\
\hline$P g m-2($ FS $\times$ FS) & 6 & 9 & -- & 5 & $1: 2: 1$ & 0.100 & $0.90-0.75$ \\
\hline$P g m-3$ (FS $\times$ FS) & 4 & 11 & - & 5 & $1: 2: 1$ & 0.100 & $0.90-0.75$ \\
\hline
\end{tabular}

${ }^{2} \mathrm{~F}=$ the fastest migrating allele at the locus; $\mathrm{M}=$ an intermediately migrating allele; $\mathrm{S}=$ the most slowly migrating allele.

Seedlings from putative crosses of 'Smooth Cayenne' $\times$ 'Cambray' and 'Cambray' $\times$ self. Parentheses indicate allelic combinations for parents at the locus. 

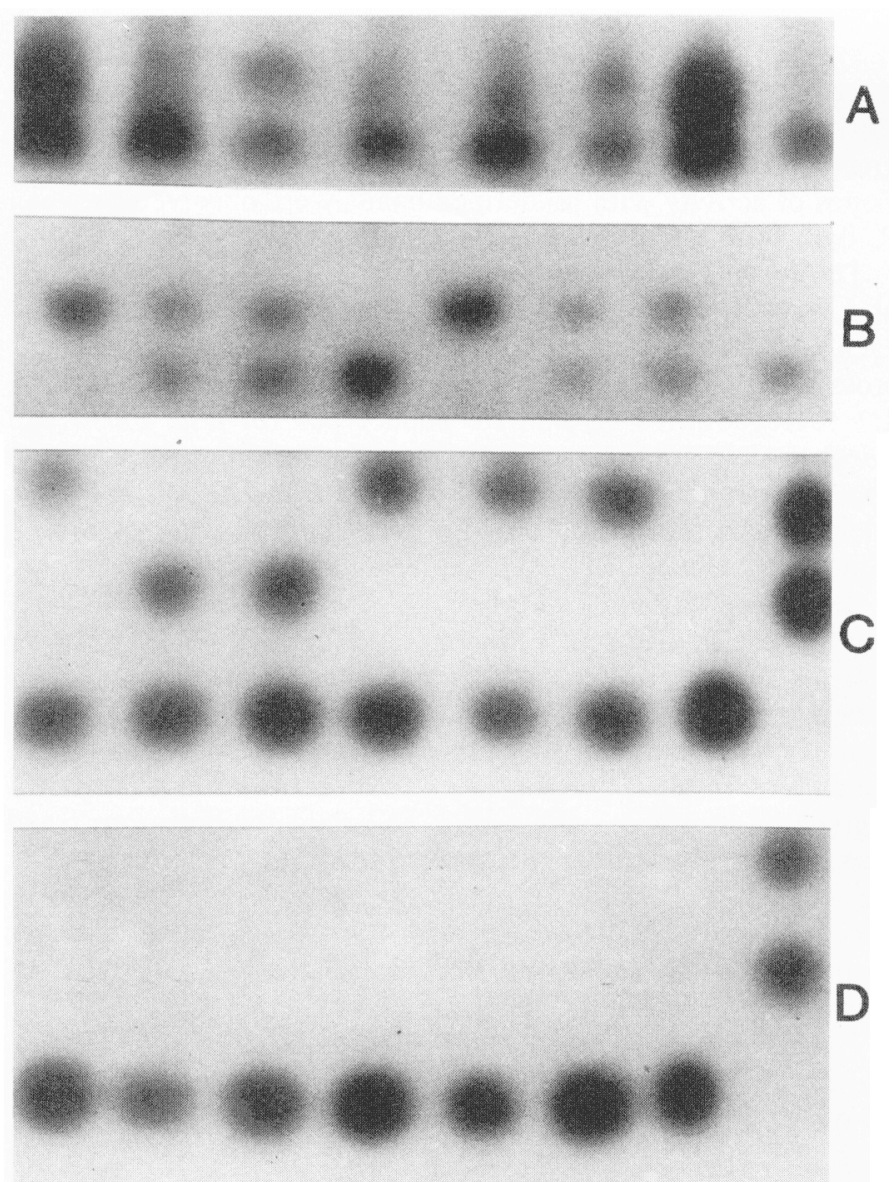

Fig. 2. PER and PGM patterns observed in pineapple progenies. In each case, from right to left are samples from 'Smooth Cayenne', 'Cambray', and progeny plants. (A, C) Progeny from the putative cross 'Smooth Cayenne' $\times$ 'Cambray' for Per-2 and Pgm-1, respectively. (B, D) Progeny from the putative cross 'Cambray' $x$ self for Per-2 and Pgm-1, respectively:

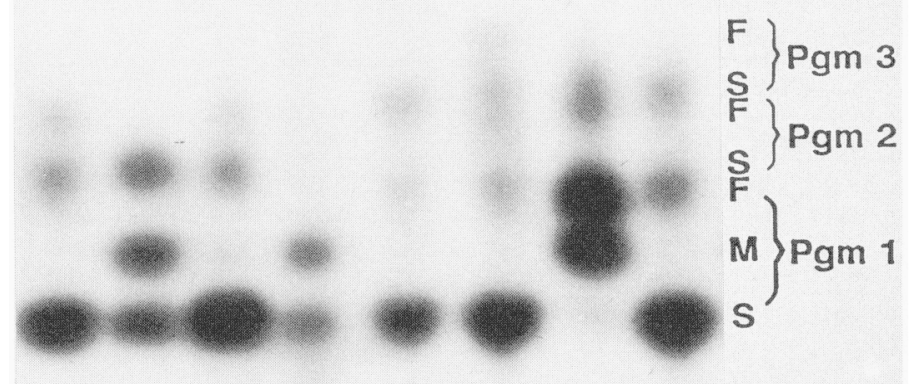

Fig. 3. PGM banding patterns observed in pineapple. Anode is at bottom' of figure.

exception is Camellia japonica L., where a third locus was reported by Wendel and Parks (1982). In this study, it was found that the PGM variability observed in Ananas could also be explained by hypothesizing a monomeric enzyme with three loci present. Locus Pgm-1 would be composed of five alleles, while

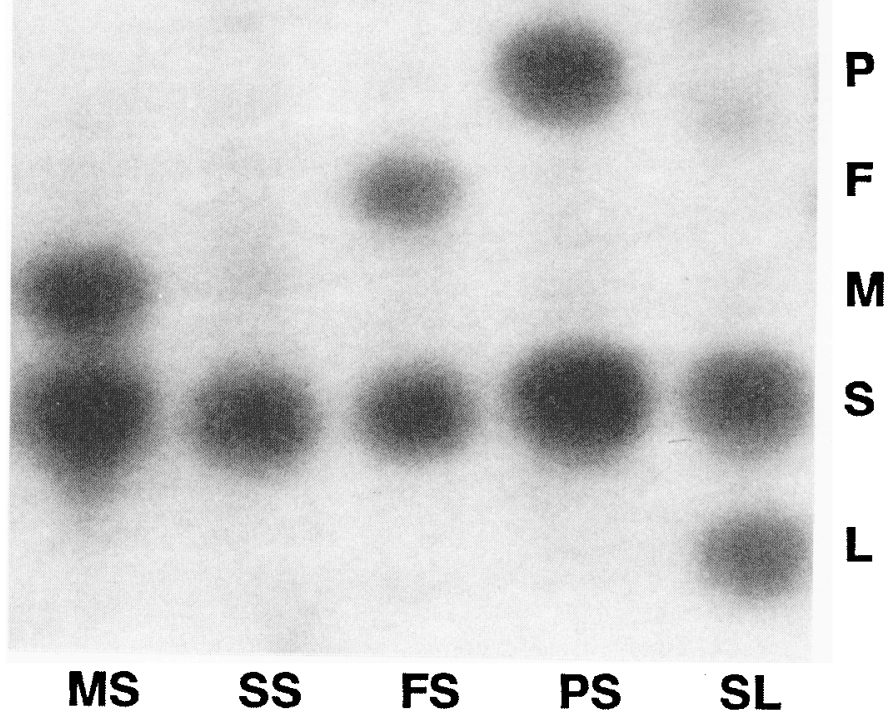

Fig. 4. Variation in the Pgm-1 region in Ananas genotypes. Anode is at bottom of figure. The two fainter-staining anodal bands in the last lane are from Pgm-2.

Pgm-2 and Pgm-3 would each have two allelic forms. Bands corresponding to the Pgm-1 locus gave consistent and clear resolution. In some instances, bands corresponding to Pgm-2 and Pgm-3 overlapped, complicating the characterization of certain genotypes.

'Smooth Cayenne' is heterozygous for Pgm-1 (FM) and homozygous for Pgm-2 (FF) and Pgm-3 (SS). Conversely, 'Cambray' is homozygous for Pgm-1 (SS) and heterozygous for Pgm-2 and Pgm-3 (FS). The 'Smooth Cayenne'-derived population showed a 1:1 segregation ratio of phenotypes for Pgm-1 (FS : MS), Pgm-2 (FF : FS), and Pgm-3 (FS : SS), which would be expected if one of the parents is homozygous and one is heterozygous at each of the loci (Table 3; Fig. 2C). Thus, the segregation patterns at these three loci indicate that the seedlings are the result of a cross between 'Smooth Cayenne' and 'Cambray'. All 'Cambray'-derived seedlings exhibited the 'Cambray' banding pattern for Pgm-1 (Table 3; Fig. 2D). Segregation was observed for Pgm-2 and Pgm-3, and $x^{2}$ values for both loci showed a very close fit to the 1:2:1 (FF : FS : SS) ratio expected for the progeny of two heterozygotes. Thus, 'Smooth Cayenne' could not have been the pollen parent in this cross, and the PGM banding patterns exhibited segregation ratios that corroborate the hypothesis that the seedlings are indeed the result of selfing.

Self-incompatibility in pineapple is due to inhibition of pollen-tube growth in the upper third of the style. It is gametophytically controlled by a single $S$ locus with multiple alleles (Brewbaker and Gorrez, 1967). In general, pineapples set no seed when self-pollinated but can set seed when crossed (Collins, 1960). Pareja (1968) suggested that the frequent occurrence of seeds in 'Cambray' may be due to self-compatibility with pollinization being accomplished by mites. The isozyme banding patterns of the seedling population obtained from 'Cambray' are further evidence of the self-compatibility of this cultivar. 
Linkage analysis. Linkage analysis was carried out between the PER and PGM loci. Chi-square analysis by contingency tables showed that the observed ratios fit ratios expected for independent assortment (data not shown).

Species identification. Five of the seven species gave consistent and individual banding patterns for PER and PGM (Table 1). The lack of intraspecific variability observed in the isozyme banding patterns of A. ananassoides, A. bracteatus var. tricolor, A. lucidus, A. nanus, and A. parguazensis may have been due to the low sample number (two) used to characterize each species, However, there are other possible explanations. The lack of variability could be due to the strict classification system used to distinguish these species (Smith and Downs, 1979). Only individuals that exactly fit the description, which includes leaf, flower, and fruit morphology and growth habit, are included. Also, all, of these species are self-pollinated (Collins, 1960; Smith and Downs, 1979), which might lead to a decrease in heterozygosity.

Two of the species displayed intraspecific polymorphism. Ananas comosus, which includes all of the commercial pineapple cultivars, exhibited high levels of polymorphism, particularly for the Pgm-1 locus. The amount of polymorphism observed within this species may be attributed to the classification system used to distinguish the species. Smith (1961) separates A. comosus from the other Ananas spp. by the length of the fruit, i.e., $>15 \mathrm{~cm}$. Thus, in this classification system, this species includes all the edible pineapples, regardless of other morphological differences such as leaf color, fruit morphology, and presence or absence of spines. Also, as discussed above, A. comosus is typically self-incompatible, with obligate out-crossing favoring a high degree of allelic heterogeneity.

Ananas monstrosus was originally described by Carriere (1870) and is included in the latest classifications by Smith (1961) and Smith and Downs (1979). The description was based on a single individual plant. It differs from typical A. comosus (pineapple) only in that the fruit lacks a crown. Based on growth habit and leaf and fruit morphology, the two plants representing A. monstrosus used in this study appear to be crown mutations of 'Perola' and 'Red Spanish' pineapple. The PER and PGM banding patterns observed for these plants are also typical of 'Perola' and 'Red Spanish'. The validity of A. monstrous as a species has been previously questioned by one of the authors (Antoni DeWald, 1983), who found mutations in other pineapple cultivars that mimic the distinguishing crownless characteristic of A. monstrous.

Characterization and classification of plant introductions. The feral types (PIs) characterized electrophoretically were grouped in putative taxonomic classifications based on their morphological characteristics (Table 2). The full range of isozymic polymorphism at each of the three PGM loci was represented in this diverse collection of genotypes. Two of the Pgm-1 alleles, L and $\mathrm{P}$, were observed only in the PIs and were not present in any of the species or cultivars examined.

Isozyme genotypes were helpful in characterizing this collection of germplasm. Many of the feral types had PGM genotypes that were in agreement with those of the species in which they had been tentatively placed. This was particularly true of those classified as A. comosus. However, there were some new allelic combinations present in these PIs that had not been observed previously. For example, PI 095 had a unique Pgm-1 genotype of FF. This is a typical pineapple type that produces large, conical, 3-kg fruit. The two sampled plants of this introduction were collected from a small plot of plants being cultivated by the Piaroas Indian River community of El Gavilan. The region is an isolated portion of dense tropical forest located in the central region of the Amazonian Territory in southern Venezuela. The cultivated plants were reportedly collected from the wild by the local Indians.

The unique Pgm-1 genotype MM was observed in the two plants of PI 487443. These plants were collected from the tropical rain forest region of San Carlos de Rio Negro, in the southernmost portion of Venezuela on the Brazilian border. Two other introductions, PI 487440 and PI 487445, were also collected from this location. Their genotypes at the Pgm-1 locus were both heterozygous MS. All three introductions from this location are smooth-leaved pineapples with similar growth habits. It appears likely that hybridization between two plants with MS Pgm-1 genotypes gave rise to PI 487443.

Isozymes were useful in identifying plant introductions that may contain genes not present in cultivated pineapple types. The Pgm- 1 allele L appeared in PI 072-1 (ML) and PI 085 (SL). These introductions were collected from the southeastern portion of Venezuela. All of the plants have leaves with few spines and bear purple fruit. Based on these morphological characteristics, they would be included in the "Spanish" horticultural group of pineapples.

The Pgm-1 allele P was observed only in PI 115. This introduction is particularly interesting. Morphologically, these plants appear intermediate between the primitive A. ananassoides and the domestic A. comosus. The plants were collected in the wild from a large homogeneous population of plants growing in an arid sandy region near the Cunavichito River in the Apure State of southwestern Venezuela.

Plant introductions 046,079, and 094; 097 and 108; and 064 were grouped under A. ananassoides, A. parguazensis, and A. nanus, respectively, because of their phenotypic similarities to these species (Table 2). When these introductions were characterized electrophoretically, the observed banding patterns at the Pgm-1 locus were all identical with those observed in the valid individuals of the species. However, differing isozyme genotypes were recorded for these putative species members at both the Pgm-2 and Pgm-3 loci. The morphological similarities of the PIs to the valid members of the respective species are evidence that they should be considered valid members of the species. This grouping, in turn, would indicate that the isozyme phenotypes of these species are not invariant.

Plant introductions 116, 117, 188, 189, 193, and 25291 were grouped in the category "Others" (Table 2) because they exhibited little morphological similarity to any of the valid Ananas spp. This diverse collection of genotypes showed considerable polymorphism for the three PGM loci analyzed, but no unique alleles.

In conclusion, we have investigated various isozyme buffer and staining systems for use with Ananas. Five isozyme loci have been identified and characterized. These loci have been useful for the characterization and classification of species and PIs already in hand. They should also be useful in the evaluation of any further germplasm collected. Several other isozyme staining systems have been identified where well-resolved banding patterns can be obtained. The collection of new Ananas types may extend their usefulness by revealing polymorphisms in the presently monomorphic systems and allowing the genetic analysis of malate dehydrogenase. Finally, the isozyme studies confirmed the existence of self-compatibility in 'Cambray', showing that not all domestic pineapple cultivars are obligately self-incompatible. 


\section{Literature Cited}

Antoni, M.G. 1983. Taxomony and cytogenetics of pineapple. MS Thesis, Univ. of Florida, Gainesville.

Brewbaker, J.L. and D.D. Gorrez. 1967. Genetics of self-incompatibility in the monocot genera Ananas (pineapple) and Gasteria. Amer. J. Bet. 54:611-616.

Cardy, B. J., C.W. Stuber, and M.M. Goodman. 1981. Techniques for starch gel electrophoresis of enzymes from maize (Zea mays L.). Inst. Stat. Mimeo Ser. no. 1317, North Carolina State Univ., Raleigh.

Carriere, E.A. 1870. Ananassa monstrosa. Rev. Hort. 42:288-289.

Collins, J.L. 1960. The pineapple. Leonard-Hill, London.

DeWald, M.G. 1988. Identification of pineapple cultivars by isozyme genotypes. J. Amer. Soc. Hort. Sci. 113:935-938.

Durham, R. B., G.A. Moore, and W.B. Sherman. 1987. Isozyme banding patterns and their usefulness as genetic markers in peach. J. Amer. Soc. Hort. Sci. 112:1013-1018.

Leal, F. and M.G. Antoni. 1980. Especies del genero Ananas: Origen y distribuciór geográfica. Proc. Amer. Soc. Hort. Sci., Trop. Reg. 24:103-106.

Loukas, M. and C.A. Pontikis. 1979. Pollen isozyme polymorphism in types of Pistacia vera and related species as an aid in taxomony. J. Hort. Sci. 54:95-102.

Melville, J.C. and J.G. Scandalios. 1972. Maize endopeptidase: Genetic control, chemical characterization and relationship to an endogenous trypsin inhibitor. Biochem. Genet. 7:15-31.

Pareja, J.M. 1968. Polinización en la pina Cambray. Trabajo de graduación, Univ. Central del Ecuador, Quito.

Scandalios, J.G. 1969. Genetic control of multiple molecular forms of enzymes in plants: A review. Biochem. Genet. 3:37-79.

Shaw, C.R. and R. Prasad. 1970. Starch gel electrophoresis-A compilation of recipes. Biochem. Genet. 4:297-320.

Smith, L.B. 1961. Notes on Bromeliaceae. Phytologia 8:12.

Smith, L.B. and R.J. Downs. 1979. Flora Neotropica: Bromelioideae (Bromeliaceae). Monogr. no. 14, Part 3. The New York Botanical Garden, New York.

Tanksley, S.D. and T.J. Orton. 1983. Isozymes in plant genetics and breeding, Part B. Elsevier, Amsterdam.

Vallejos, C.E. 1983. Enzyme activity staining, p. 469-516. In: S.D. Tanksley and T.J. Orton (eds.). Isozymes in plant genetics and breeding, Part A. Elsevier, Amsterdam.

Wendel, J.F. and C.R. Parks. 1982. Genetic control of isozyme variation in Camellia japonica L. J. Hered. 73:197-204. 